\title{
Patient-controlled analgesia after laparoscopic and open cholecystectomy
}

Laparoscopic cholecystectomy (LC) offers advantages over open cholecystectomy (OC) of more rapid patient recovery. The comparative amount of pain that patients must endure after each of these procedures is not clear. We retrospectively analysed the use of patient-controlled analgesia (PCA) of an unselected sample of patients having either $L C$ or $O C$ procedures to quantitate morphine use, as well as pain and sedation scores in the postoperative period. The hospital charts, anaesthetic records and the PCA records of 40 patients having either $L C(n=19)$ or $O C(n=21)$ were analysed retrospectively. The use of PCA morphine was standardized and consisted of a loading dose of $5 \mathrm{mg}$, bolus doses of $1.5 \mathrm{mg}$ and a lockout period of five minutes. By the morning of postoperative day one, OC patients had used $38.0 \pm 11.7$ (mean $\pm S D$ ) mg compared with 23.7 $\pm 15.3 \mathrm{mg}$ in LC patients $(P<0.05)$. The rates of $P C A$ morphine use in the first two postoperative hours were $4.66 \pm 2.6$ $\mathrm{mg} \cdot \mathrm{hr}^{-1}$ and $7.04 \pm 2.7 \mathrm{mg} \cdot \mathrm{hr}^{-1}$ for $L C$ and $O C$ patients, respectively $(P<0.05)$. The rates of morphine use averaged over the day of surgery were $1.28 \pm 0.8 \mathrm{mg} \cdot \mathrm{hr}^{-1}$ and 2.33 $\pm 0.8 \mathrm{mg} \cdot \mathrm{hr}^{-1}$ for LC and OC patients ( $P<0.05$ ). Despite higher PCA morphine use in $O C$ patients, their pain scores were higher while their sedation scores were comparable. These data suggest that laparoscopic cholecystectomy is associated with less pain than open cholecystectomy in the day after surgery.

\section{Key words}

ANALGESIA: postoperative, PCA;

ANALGESICS: morphine;

PAIN: postoperative, measurement;

SURGERY: cholecystectomy.

From the Departments of Anaesthesia, Sir Mortimer B. DavisJewish General Hospital*, and McGill University†, Montreal, Quebec.

Presented in part at the 67th Congress of the International Anesthesia Research Society, San Diego, March 1993.

Address correspondence to: Dr. Saul Wiesel, School of Medicine, Department of Anesthesiology and Critical Care Medicine, Surge Building, Albuquerque, New Mexico 871315216.

Accepted for publication 26th August 1994.
La cholécystectomie par laparoscopie (CL) offre l'avantage d'une récupération plus rapide sur la cholécystectomie ouverte $(C O)$. Lintensité comparative de la douleur qui suit chacune des interventions n'a pas été déterminée. Nous avons, de façon rétrospective, analysé l'utilisation de l'analgésie auto-contrôlée (PCA) chez un groupe de patients ayant subi la LC ou la CO pour quantifier, à la période postopératoire, l'utilisation de la morphine, aussi bien que les scores de douleur et de sédation. Chez 40 patients, les dossiers hospitaliers, d'anesthésie et de l'unité du contrôle de la douleur ont été analysés en rétrospective après $C L(n=19)$ ou $C O(n=21)$. L'administration de la morphine était standardisée et consistait en une dose initiale de $5 \mathrm{mg}$, des bolus de $1,5 \mathrm{mg}$ et un intervalle de privation de cing minutes. Le matin du premier jour postopératoire, les patients $C O$ ont utilisé $38,0 \pm 11.7$ (moyenne $\pm S D$ ) $m g$ de morphine comparativement à 23,7 $\pm 15,3 \mathrm{mg}$ chez les patients $L C$ ( $P$ $<0.05$ ). Le régime d'administration de la morphine au cours des deux premières heures postopératoires a été de 4,66 $\pm 2,6$ $\mathrm{mg} \cdot \mathrm{hr}^{-1}$ et $7,04 \pm 2,7 \mathrm{mg} \cdot \mathrm{hr}^{-1}$ pour les $\mathrm{CL}$ et $\mathrm{CO}$ respectivement $(P<0,05)$. Le jour de la chirurgie, la vitesse d'administration de la morphine a été de $1,28 \pm 0,8 \mathrm{mg} \cdot \mathrm{hr}^{-1}$ et $2,33 \pm 0,8 \mathrm{mg} \cdot \mathrm{hr}^{-1}$ pour les patients LC et $O C(P<$ 0.05 ). Malgré l'utilisation plus importante de morphine avec la PCA chez les CO, leurs scores de douleur ont été plus élevés et les scores de sédation comparables. Ces données suggèrent que le jour de la chirurgie, la cholécystectomie par laparoscopie est moins douloureuse que la cholécystectomie ouverte.

The laparoscopic approach to cholecystectomy (LC) has resulted in a number of advantages including shorter hospitalization and a more rapid return to normal activity ${ }^{1}$ than after traditional open cholecystectomy (OC). Furthermore, LC may lead to less deterioration in postoperative pulmonary function, ${ }^{2}$ and lower morbidity and mortality rates. ${ }^{3}$ While it is generally perceived that postoperative pain after LC is less than after OC, few data exist to support this. It has been our observation and that of others ${ }^{4}$ that a proportion of LC patients have considerable pain in the immediate postoperative period following emergence from anaesthesia and may require substantial amounts of opioids to gain relief. This has 
led us to offer patient-controlled analgesia (PCA) using $i v$ morphine to both $\mathrm{LC}$ and $\mathrm{OC}$ patients. Patients using PCA can self-administer small doses of $i v$ opioid in response to their own perceived pain. We designed this retrospective, controlled study to compare the postoperative pain in an unselected sample of patients having either LC or OC using the criteria of (1) the requirements for PCA morphine and (2) pain and sedation scores. If the LC procedure was associated with less postoperative pain then we would expect to find reduced PCA morphine use, lower pain scores or both.

\section{Methods}

Approval of the hospital Research and Ethics Committee was obtained. The study patients consisted of adult patients who had undergone either $\mathrm{LC}$ or $\mathrm{OC}$ in our institution during the same period of time, by the same group of surgeons and had received PCA morphine by the Acute Pain Service of the Department of Anaesthesia. Patients were assigned to undergo either LC or an $\mathrm{OC}$ based on the preference of the patient, the surgeon, and the availability of laparoscopic equipment. Patients had received PCA morphine after instruction in the correct use of PCA the night prior to surgery by a nurse dedicated to the PCA service. The charts of 40 patients were drawn at random from a list of approximately 100 complete records of patients who had undergone either LC or OC and had received PCA. Retrospectively, we analysed the hospital charts, anaesthetic and PCA records of these 40 patients who had undergone LC ( $n$ $=19)$ or OC $(n=21)$.

General anesthesia was induced in all cases with thiopentone and fentanyl and maintained with isoflurane in $70 \%$ nitrous oxide and 30\% oxygen with increments of fentanyl at the discretion of the anaesthetist. Morphine was not used intraoperatively.

After arrival in the Post Anaesthesia Care Unit (PACU), PCA was initiated when the patient was alert and requesting analgesia. Routine PCA orders consisted of a loading dose of morphine $5 \mathrm{mg}$, bolus doses of 1.5 $\mathrm{mg}$ and a lockout period of five minutes. A second loading dose of morphine $5 \mathrm{mg}$ was delivered if, in the opinion of the PACU nurse, the first did not provide adequate analgesia. Continuous infusions of morphine were not used. For LC patients, PCA was used until 07:00 hr of postoperative day one (POD \#1) and discontinued in preparation for discharge. The $\mathrm{OC}$ patients continued to use PCA until 07:00 hr of postoperative day two.

Pain and level of sedation were assessed every hour for the first four hours, every two hours for the next eight hours and every four hours thereafter. Pain was assessed by the patient and recorded by the nurse using the six point McGill pain score: ${ }^{5} 0$ no pain; 1 mild pain; 2 dis-
TABLE I Demographic data

\begin{tabular}{lll}
\hline & $L C$ & $O C$ \\
\hline$n$ & 19 & 21 \\
Age yr & $47(14.62)$ & $56(15.4)$ \\
Sex Male & 5 & 8 \\
$\quad$ Female & 14 & 13 \\
ASA I/II/III & $14 / 3 / 2$ & $10 / 9 / 2$ \\
Height cm & $145.74(52.31)$ & $141.52(60.05)$ \\
Weight kg & $64.05(23)$ & $72.92(25.13)$ \\
Haemoglobin $\mathrm{g} \cdot \mathrm{L}^{-1}$ & $137.84(12.13)$ & $133.57(13.21)$ \\
Bilirubin $\mathrm{mg} \cdot \mathrm{L}^{-1}$ & $14.78(16.36)$ & $14.48(12.10)$ \\
\hline
\end{tabular}

Continuous data mean (SD). No differences found between groups. LC laparoscopic cholecystectomy; OC open cholecystectomy.

comforting pain; 3 distressing pain; 4 horrible pain; 5 excruciating pain. Level of sedation was assessed and recorded by the nurse using a five point scale: 1 wide awake; 2 drowsy; 3 dozing intermittently; 4 mostly sleeping; and 5 only awakens when stimulated.

The loading dose(s) of morphine were included in the calculations of PCA morphine use. Cumulative PCA morphine use was analysed at two and at eight hours after surgery and at 07:00 $\mathrm{hr}$ the morning of postoperative days one and two, to derive data for the day of surgery (POD \#0) and POD \#1, respectively. The rate of morphine consumption per hour was calculated for the first two hours after surgery, the period from two hours to eight hours after surgery and overnight from eight hours after surgery to $07: 00 \mathrm{hr}$ next morning. Pain and sedation scores were analysed for the times defined by the first two postoperative hours and the mean values for the entire periods of the day of surgery and POD \#1. Since 18 of the $19 \mathrm{LC}$ patients were discharged on the morning of the first postoperative day, only data from the OC patients could be analysed for POD \#1.

Statistical analysis was by Chi-square and ANOVA with the unpaired Student's $t$ test for dicotomous and continuous data, respectively. A value of $P<0.05$ was considered statistically significant.

\section{Results}

The LC and OC group patients did not differ demographically (Table I). The duration of LC was longer than OC $(P<0.05)$ (Table II). In the PACU, there was no difference between LC and OC patients in the time before PCA was initiated (Table III). Three patients required a second loading dose of morphine to achieve analgesia (1 LC, 2 OC).

Patients undergoing $O C$ required more cumulative PCA morphine than LC patients $(P<0.05)$ (Figure 1) and more PCA morphine during all time intervals $(P$ $<0.05$ ) (Figure 2). 
TABLE II Intraoperative variables

\begin{tabular}{lll}
\hline & $L C$ & $O C$ \\
\hline$n$ & 19 & 21 \\
Thiopentone mg & $318.16(105.48)$ & $338.33(139.72)$ \\
Duration of surgery min & $100.58(31.84)$ & $73.33(28.5)^{*}$ \\
Fentanyl use during & & \\
$\quad$ surgery $\mu \mathrm{g} \cdot$ min $^{-1}$ & $2.58(2.11)$ & $2.67(1.36)$ \\
Droperidol mg & $0.98(0.80)$ & $0.87(0.75)$ \\
\hline
\end{tabular}

$* P<0.05$ between groups.

Mean (SD).

LC: laparoscopic cholecystectomy; OC: open cholecystectomy.

TABLE III PCA use

\begin{tabular}{lll}
\hline & $L C$ & $O C$ \\
\hline$n$ & 19 & 21 \\
Time to PCA min & $36.0(44.26)$ & $38.48(39.41)$ \\
$\begin{array}{l}\text { Duration of PCA use hr } \\
\text { Pain score 0 to 2 hr }\end{array}$ & $19.09(6.47)$ & $39.2(5.19)^{*}$ \\
$\quad$ postoperative & $2.01(0.98)$ & $2.66(0.956)^{*}$ \\
Pain score day of surgery & $1.03(0.56)$ & $1.79(0.75)^{*}$ \\
$\begin{array}{l}\text { Pain score POD \#l } \\
\text { Sedation score 0 to 2 hr }\end{array}$ & & $1.09(0.63)$ \\
$\quad$ postoperative & $2.27(0.85)$ & $1.86(0.69)$ \\
Sedation score day of & & $2.22(0.73)$ \\
$\quad$ surgery & & $1.71(0.78)$ \\
Sedation score POD \#1 & $2.50(0.68)$ &
\end{tabular}

$* P<0.05$ between groups.

All data expressed as mean (SD).

LC laparoscopic cholecystectomy; OC open cholecystectomy. POD \#1 postoperative day one. Pain and sedation were scored as per the

Methods section of the text. Data do not exist for LC patients for POD \#1 because 18 of 19 patients had been discharged by the morning of POD \#1.

Pain scores in $\mathrm{OC}$ patients were higher than LC patients during the first two postoperative hours and when averaged over the entire day of surgery (Table III). Sedation scores were not different between groups at any time (Table III).

\section{Discussion}

The use of intravenous PCA opioids may be useful in reducing failures that occur with traditional postoperative pain management. ${ }^{6}$ Intravenous PCA opioids have been used to titrate the pain of labour as it evolves with cervical dilatation, ${ }^{7}$ to compare the potency of opioid ${ }^{8}$ and nonopioid analgesics, 9,10 and to determine the minimum effective concentration of morphine for postoperative analgesia."

Our data suggest that PCA opioid requirements are lower in patients having LC surgery than with $O C$ surgery, and that this is associated with lower pain scores. Patients undergoing $\mathrm{OC}$ required a mean of $2.33 \pm 0.8$

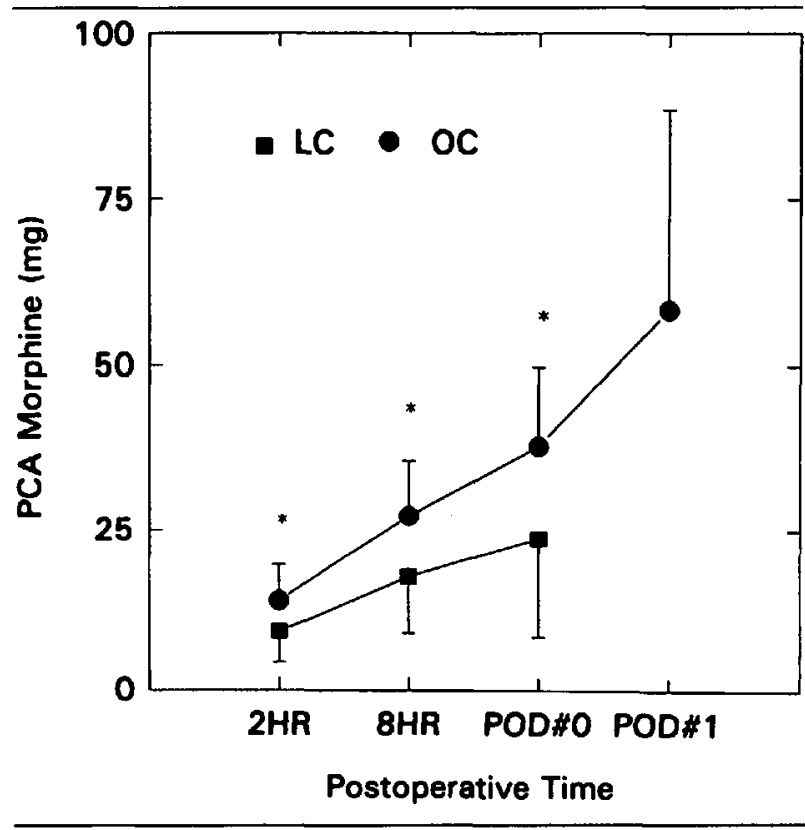

FIGURE 1 Cumulative PCA morphine requirements. Data presented as mean $\pm \mathrm{SD} . * P<0.05$ between groups. LC laparoscopic cholecystectomy; OC open cholecystectomy. Postoperative times examined were two hours ( $2 \mathrm{hr})$, eight hours ( $8 \mathrm{hr})$, day of surgery. which ended at $07: 00 \mathrm{hr}$ of the day after surgery (POD $\# 0$ ), and postoperative day 1 (POD \#1). Data do not exist for LC patients for POD \#1 because 18 of 19 patients had been discharged the morning of POD \#I.

$\mathrm{mg} \cdot \mathrm{hr}^{-1}$ PCA morphine on the day of surgery, which is similar to the figure of $2.6 \pm 1.2 \mathrm{mg} \cdot \mathrm{hr}^{-1}$ morphine reported by Tamsen et al. ${ }^{12}$ after major abdominal surgery.

A recent prospective study did not support our observation of decreased opioid requirements and lower pain scores in LC than in OC patients. ${ }^{2}$ Pain scores did not differ at any time in the first $24 \mathrm{hr}$ after surgery and the requirements for opioids in the first $24 \mathrm{hr}$ were similar. ${ }^{2}$ The use of large doses of $i m$ morphine instead of PCA morphine in that study may have obscured potential differences in opioid requirements.

This study may be criticised because patients were not assigned to either $\mathrm{LC}$ or $\mathrm{OC}$ in a randomized, prospective manner. The reputed advantages of the LC technique were so obvious to surgeons and to the public, that a prospective randomized study was not considered ethical and patients would have been difficult to enrole.

Is PCA a useful form of postoperative analgesia for LC patients? These data suggest that although PCA morphine use and pain scores were lower in LC than in OC patients, substantial overlap exists between groups. The advantages of PCA opioids compared with im narcotics for abdominal surgery are subjectively better analgesia $^{13-15}$ with equal ${ }^{13}$ or less sedation. ${ }^{16}$ Compared with epidural morphine, however, PCA morphine may provide 


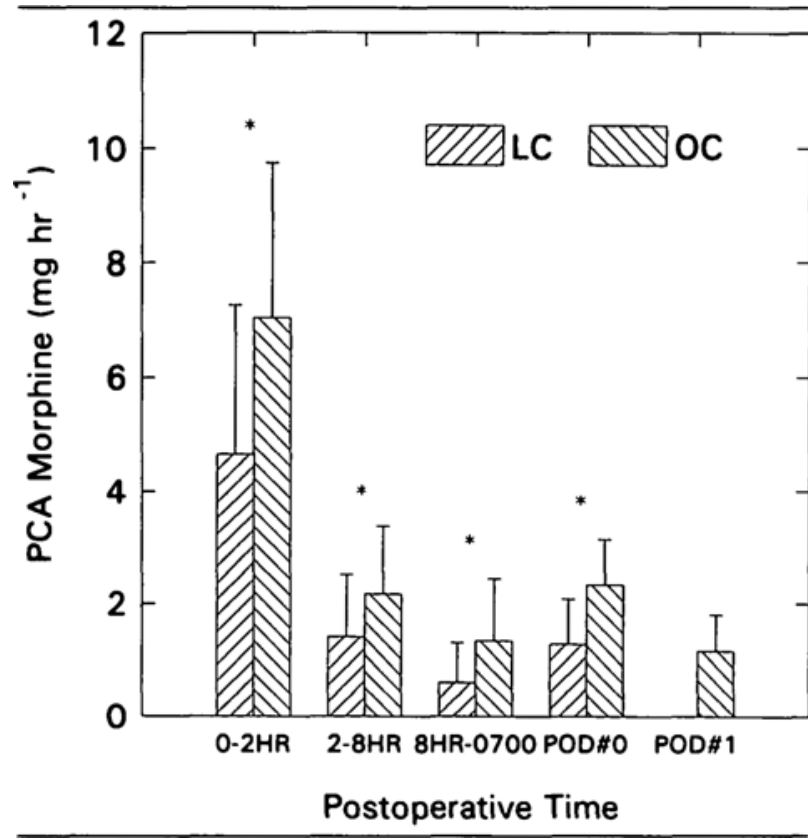

FIGURE 2 PCA morphine requirements for postoperative time intervals. Data presented as mean $\pm S D$. LC: laparoscopic cholecystectomy; OC: open cholecystectomy. Postoperative time intervals examined were the first two postoperative hours $(0-2 \mathrm{hr})$, from two to eight hours postoperative ( $2-8 \mathrm{hr}$ ), from 8 hours postoperative to $07: 00 \mathrm{hr}$ the morning after surgery $(8 \mathrm{hr}-0700)$, the mean of all the day of surgery (POD $\# 0$ ), and the mean of all of postoperative day I (POD \#1). Data do not exist for LC patients for POD \#1 because 18 of 19 patients had been discharged by the morning of POD \#1.

$* P<0.05$ between groups.

inferior analgesia after cholecystectomy. ${ }^{17}$ As in the case of the present study, side effects such as sedation may limit the maximum dose of $i v$ opioids that are selftitrated. ${ }^{17}$

In conclusion, this retrospective study compared the use of PCA morphine in a random sample of laparoscopic and open cholecystectomy patients. Morphine requirements were reduced and lower pain scores resulted with the laparoscopic technique.

\section{Acknowledgements}

The authors gratefully acknowledge Dr. A. Paul Kliffer MD FRCPC, Dr. Simcha J. Kleiman MD FRCPC and Maria Soucci BSc who were instrumental in setting up the PCA programme and the assistance of the PCA nurses Wendy Blake RN, Nathalie Scheffer RN and the nurses of the PACU. Also, we thank Dr. Gordon Minton for his editorial assistance during the preparation of this manuscript.

\section{References}

1 Gadacz TR, Talamini MA. Traditional versus laparoscopic cholecystectomy. Am J Surg 1991; 161: 336-8.
2 Rademaker BM, Ringers J, Odoom JA, de Wit LT, Kalkman CJ, Oosting J. Pulmonary function and stress response after laparoscopic cholecystectomy: comparison with subcostal incision and influence of thoracic epidural analgesia. Anesth Analg 1992; 75: 381-5.

3 Holohan TV. Laparoscopic cholecystectomy. Lancet 1991; 338: 801-3.

4 Rose DK, Cohen MM, Soutter DI. Laparoscopic cholecystectomy: the anaesthetist's point of view. Can J Anaesth 1992; 39: 809-15.

5 Katz J, Melzack R. Measurement of pain. Anesthesiology Clinics of North America 1992; 10: 229-46.

6 Melzack R, Abbott FV, Zackon W, Mulder DS, Davis $M W L$. Pain on a surgical ward: a survey of the duration and intensity of pain and the effectiveness of medication. Pain 1987; 29: 67-72.

7 Evans JM, Rosen M, MacCarthy J, Hogg MIJ. Apparatus for patient-controlled administration of intravenous narcotics during labour. Lancet 1976; 1: 17-8.

8 Sinatra RS, Lodge $K$, Sibert $K$, et al. A comparison of morphine, meperidine, and oxymorphone as utilized in patient-controlled analgesia following cesarean delivery. Anesthesiology 1989; 70: 585-90.

9 Tamsen A. Patient controlled analgesia: a review of the current state of knowledge. Seminars in Anesthesia 1986; 5: $100-7$.

10 Segstro $R$, Morley-Forster $P K, L u G$. Indomethacin as a postoperative analgesic for total hip arthroplasty. Can J Anaesth 1991; 38: 578-81.

11 Dahlström B, Tamsen A, Paalzow L, Hartvig P. Patientcontrolled analgesic therapy, Part IV: pharmacokinetics and analgesic plasma concentrations of morphine. Clin Pharmacokinet 1982; 7: 266-79.

12 Tamsen A, Hartvig P, Fagerlund C, Dahlström B, Bondesson $U$. Patient-controlled analgesic therapy: clinical experience. Acta Anaesthesiol Scand 1982; 74: S157-60.

13 Bollish SJ, Collins CL, Kirking DM, Bartlett RH. Efficacy of patient-controlled versus conventional analgesia for postoperative pain. Clinical Pharmacy 1985; 4: 48-52.

14 Wasylak TJ, Abbott FV, English MJM, Jeans M-E. Reduction of postoperative morbidity following patientcontrolled morphine. Can J Anaesth 1990; 37: 726-31.

15 Whealley RG, Shepherd D, Jackson IJB, Madej TH, Hunter $D$. Hypoxaemia and pain relief after upper abdominal surgery: comparison of i.m. and patient-controlled analgesia. Br J Anaesth 1992; 69: 558-61.

16 Bennett RL, Batenhorst RL, Bivins BA, et al. Patientcontrolled analgesia. A new concept of postoperative pain relief. Ann Surg 1982; 195: 700-5.

17 Loper KA, Ready LB, Nessly M, Rapp SE. Epidural morphine provides greater pain relief than patient-controlled intravenous morphine following cholecystectomy. Anesth Analg 1989; 69: 826-8. 